Article

\title{
Factor Analysis of Packaging Visual Design for Happiness on Organic Food-Middle-Aged and Elderly as an Example
}

\author{
Jui-Che Tu, Hsing-Tzu Chang * and Shu-Bei Chen \\ Graduate School of Design National Yulin University of Science and Technology, Yunlin 64002, Taiwan; \\ tujc@yuntech.edu.tw (J.-C.T.); teresa6wei@gmail.com (S.-B.C.) \\ * Correspondence: ivy89231168@yahoo.com.tw
}

Received: 11 May 2019; Accepted: 10 June 2019; Published: 13 June 2019

\begin{abstract}
This study explored the visual images that affect middle-aged and elderly consumer groups in organic food packaging design, and summarized the happiness of visual design elements for organic food as a reference for design. This study used expert interviews, the KJ method to collect image vocabulary and select representative samples, and the Semantic Differential method (SD method) to evaluate the happiness image of organic food. Then, the questionnaire survey method was used to investigate the subjects' attention regarding happiness in the visual design elements of organic food. This study adopted one-way ANOVA to understand the differences of consumers' visual images for different organic food packages. The results show that the living patterns of the consumer groups in organic food packaging design can be classified into four groups. The "Self-actualization Group" thinks that happiness organic food packaging is healthy, reassuring, environment-friendly, healing, comfortable, and novel. The "Caring for Health Group" believes that happiness organic food packaging is healthy, reassuring, and environmentally friendly. The "Lohas Food Safety Group" believes that happiness organic food is packaged in a healthy, simple, and environment-friendly way. The "Extroverted Loyalty Group" believes that happiness organic food packaging is healthy, comfortable, professional, simple, environment-friendly, and novel.
\end{abstract}

Keywords: sense of happiness; organic food; living pattern; ANOVA

\section{Introduction}

The global population aging problem is becoming more and more serious, and various countries are gradually moving towards a super-aged society; 13 countries will reach the standard of a super-aged society by 2020 and 34 countries will reach the standard by 2030 [1]. In view of people's increasing awareness of health and the aging population, the market demand for organic and health care products is increasing rapidly. In recent years, people have paid more and more attention to active and positive psychology. At the same time, various disciplines and fields have paid more attention to the research on happiness. In the design field, packaging is considered to be the performance space that can show "happiness design" [2]; packaging can convey the information of commodities and affect consumers' feelings towards the products. In addition to helping people have the positive effects of calmness, inspiration, and revelation by combining material happiness with spiritual happiness, packaging can make people's brain waves show a gradually activated state when the packaging design initiates the tactile, auditory, and olfactory senses to stimulate appreciation [3,4]. The most important items in design include shape and color, as well as the inner levels of how people will feel, meaning the design object of a happiness design is the carrier [5]. It is a resource that allows people to immerse themselves in experiencing happiness and a process for people to receive happiness, and it is used to realize the 
life goals pursued by people and make life more meaningful, as seen in Figure 1. Thus, compared with the external factors that affect psychological happiness, psychological health is the internal factor that affects happiness the most from the personal level [6,7].

Nowadays, Orange Technology has entered the era of happiness design. In order to improve the pressure faced by middle-aged and elderly people, this study explored the semantic analysis of the inner happiness of middle-aged and elderly people through lifestyle trends, and understood the design elements of visual happiness that they attach importance to, including organic food packaging. The successful happiness packaging contains material and spiritual elements, and conveys happiness to middle-aged and elderly people, which not only improves social and economic benefits, it also balances people's inner emotions, thus, improving their health psychology, spiritual satisfaction, and quality of life [8]. Based on the aforementioned research motivation, the primary purpose of the study was to investigate the visual images that affect middle-aged and elderly consumer groups in organic food packaging design, and summarize the happiness of visual design elements for organic food as a reference for design.

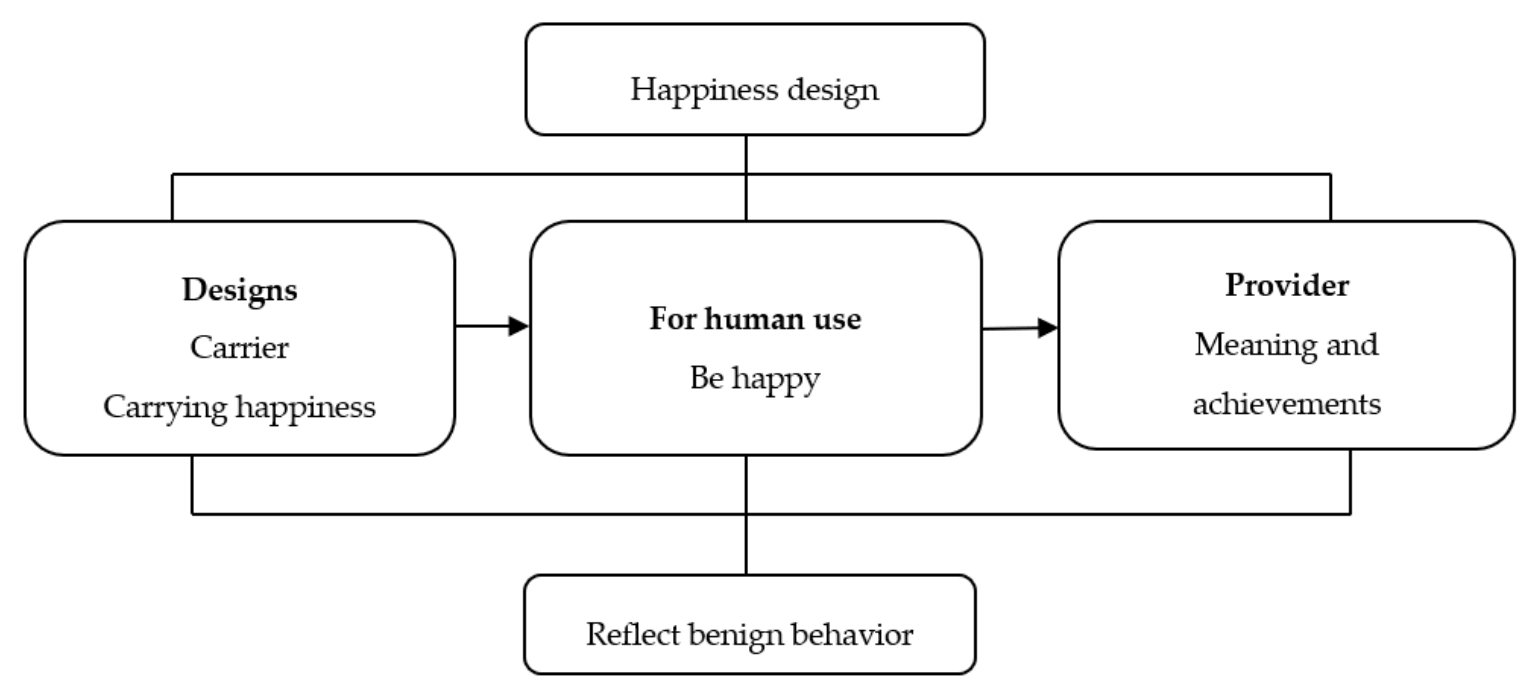

Figure 1. Process of Happiness Design Making People Happy.

\subsection{Orange Technology}

Orange Technology is a kind of technology that emphasizes people-centered and humanity-centered design, and its purpose is to practice the basic values of humanistic technology and develop industries related to happiness, health, humanistic quality, and physical and mental care. Orange is a combination of yellow and red, and these symbolic colors represent happiness and warmth, and health $[9,10]$. The Orange Technology industry includes three major categories: health technology, care technology, and happiness technology. Among them, happiness technology is the research focus of this study, which includes the industrial requirements of improving human quality and care for the body and mind (Figure 2). Happiness is an "abstract concept", like joy, pain, culture, and belief, and people have different understandings of "happiness" from different angles. A product's happiness level is divided into four major elements: cognitive happiness, perceived happiness, physiological happiness, and sensory happiness [7]. In the happiness design, the positive influences on human beings are taken as the motivation, and the factors of happiness design are discussed, as follows: favorable to human needs, life expectation, meaningful and valuable, satisfactory evaluation of emotion and life, makes people have positive effect and supportive feelings, can be tasted and enjoyed, is not a temporary pleasure, interacts with people, can obtain a sense of accomplishment, design has meaning, connotation, and affiliation, enlightens, is an experience, inspires people to be good and have the same experience as others, is activating, tasteful, and reminds people to do something, enables people to achieve their goals, and is thoughtful, satisfying, and ethical [11,12]. 


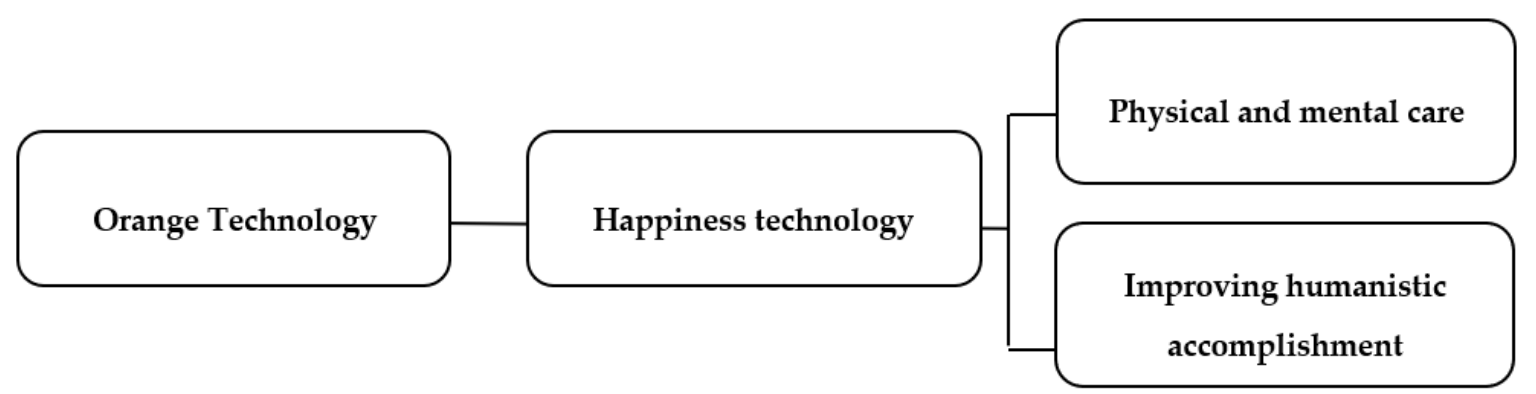

Figure 2. Happy Technology Field of Orange Technology.

\subsection{Happiness Design}

In the field of graphic commercial design, packaging is a kind of expression space that can better show "happiness design". When the differentiation of commodities themselves is disappearing, only aesthetics and visualization can create an unforgettable perception experience [13]. The essence of packaging is mainly to express the needs of consumers and customers by visual design, which can enhance the visual beauty of the image and highlight the theme and difference of the product $[14,15]$. As packaging is sometimes not necessarily a commercial behavior, it can be developed more flexibly and perceptively in use. The more specific the visual image is conveyed on the packaging, the easier it is for the receiver to understand, and while visual symbols will have different meanings and opinions for people according to the influence of personal experience and cultural background, it does not mean that the cognition of everyone is different, as people still have a common experience [16]. According to research on the variables of the effect of packaging design, benefits on brand equity, packaging visual design can be divided into six components; color, text, graphics, layout, structural modeling, and materials [17].

As each person's life experience and cognitive style are different, designers must explore each consumer's processing procedures and results of visual happiness [18,19], deduce a visual design with certain stimulating characteristics, understand the consumer's psychology, arrange the design elements into a visual design with happiness, and urge consumers to understand the contents and information of commodities according to their personal subjective experience, in order to reach understanding and judgment of products and form a meaningful and effective visual communication design of happiness $[13,20]$.

\subsection{Organic Food Packaging}

According to the preconceived notion of consumers, organic food should be planted without damaging the environment, and its packaging materials should be environmentally friendly; for example, flexible packaging can reduce the loss of food materials and sustainable environmental packaging materials, while any non-functional packaging materials should be avoided as much as possible [21-23]. Today, the new topic of organic food packaging is that the product image should enable people to obtain a sense of peace of mind and honesty, establish "happiness" for consumers, and build friendly customer loyalty, in order that, when eating organic foods, they can feel happy and pleased in their hearts, which also nourishes them, thus, achieving a win-win diet therapy effect in both body and mind. As there is no study on happiness factors in organic food packaging for middle-aged and elderly people in the above-mentioned relevant documents, this research took the activities, interests, opinions, and population variables as the basis of lifestyle, and referred to the above-mentioned relevant documents to sum up the correlation between the lifestyle of middle-aged and elderly people and the happiness visual design of organic food packaging. 


\section{Research Methodology}

\subsection{The Design of Research Instruments}

This study selected four designers with more than 10 years of experience to select and establish the adjective vocabulary and representative samples of happiness in organic food packaging (Table 1), as based on the opinions and suggestions for happiness in organic food packaging, as put forward by expert interviews. First, through the contents of expert interviews and literature discussion, an evaluation questionnaire on lifestyle and visual design elements regarding happiness in organic food packaging was compiled to determine whether the questions in the questionnaire conform to the definition of the dimensions [24,25] (Tables 2 and 3). In addition, a Likert Five-Point Scale was used to conduct the survey. The questionnaire survey found the opinions of the subjects by answering the questions in advance, and the collected questionnaires were compiled. By using the questions raised in this study, the average value of the answer to each question was imported into the IBM SPSS Statistics 20.0 edition statistical software to observe the evaluation of each factor.

Table 1. List of expert interviews.

\begin{tabular}{ccc}
\hline Interviewees & Employer & Number of Years Working in Design \\
\hline Creative Director Wang, B.N. & UP creative & 34 years \\
\hline Creative Director Pan, W. & GIDEA group & Over 10 years \\
\hline Design Director Chen, Q.W. & VORKON & 36 years \\
\hline Design Director Yu, D.G. & 2TIGERS design studio & Over 10 years \\
\hline
\end{tabular}

Table 2. Life Style Assessment Items.

\begin{tabular}{|c|c|c|}
\hline AIO Dimension & Subdimension & Question \\
\hline \multirow{3}{*}{ Activity } & Shopping & $\begin{array}{l}\text { 1. I often go shopping in organic or raw food stores. } \\
\text { 2. I am willing to spend a higher price to buy nutritious, natural, or safe food. } \\
\text { 3. I will particularly prefer to buy food or merchandise of the same brand. } \\
\text { 4. Before shopping, I will make a list of foods to be purchased in advance. } \\
\text { 5. We should shop around to avoid losses in shopping. } \\
\text { 6. When I see something I like; I will not hesitate to buy it. }\end{array}$ \\
\hline & Entertainment & $\begin{array}{l}\text { 7. In order to improve the enjoyment of life, it is worth spending more money. } \\
8 \text {. I only want to rest and relax at home during the holiday. }\end{array}$ \\
\hline & Hobby & $\begin{array}{l}\text { 9. In order to balance the intake of nutrients, I will eat healthcare food regularly. } \\
\text { 10. Food brand and advertising image will affect my purchasing behavior. } \\
\text { 11. I like to relax at home after work. } \\
\text { 12. Although I have eaten dinner, I still want to have snacks. } \\
\text { 13. I like to prepare meals with family and friends at home or outside. }\end{array}$ \\
\hline \multirow{3}{*}{ Interest } & Popular & $\begin{array}{l}\text { 14. Eating organic food is an act with the concept of environmental protection. } \\
\text { 15. It is very important for me to absorb the latest health-related information. }\end{array}$ \\
\hline & Media & $\begin{array}{l}\text { 16. I often provide the latest health information and trends to friends and relatives. } \\
\text { 17. I will buy products recommended by nutrition experts or scholars. } \\
\text { 18. I doubt the authenticity of the advertisement for a new product. }\end{array}$ \\
\hline & Achievements & $\begin{array}{l}\text { 19. I pay attention to the diet health of my family members and myself. } \\
\text { 20. If products are accompanied by production and marketing certification, it can } \\
\text { make the company aware of its responsibilities. }\end{array}$ \\
\hline Opinion & Self & $\begin{array}{l}\text { 21. I have regular health checks. } \\
\text { 22. I am satisfied with my current life. } \\
\text { 23. I do things with my own mind and do not care much about what others think. } \\
\text { 24. I will try my best to do everything best, whether I am good at it or not. } \\
\text { 25. I am a cautious person and I have to plan everything. } \\
\text { 26. It is easy for me to have a pleasant chat with people I meet for the first time. } \\
\text { 27. I will not hesitate in doing things, but will be more decisive. } \\
\text { 28. I think people should continue to make progress and study. }\end{array}$ \\
\hline
\end{tabular}


Table 2. Cont.

\begin{tabular}{|c|c|c|}
\hline AIO Dimension & Subdimension & Question \\
\hline Opinion & Products & $\begin{array}{l}\text { 29. I do not use prepared food (e.g., frozen food, canned food) when cooking. } \\
\text { 30. When buying food, I will read the ingredients of the food carefully. } \\
\text { 31. I think the government should be committed to food safety checks. } \\
\text { 32. The packaging/appearance of organic food is very attractive to me, } \\
\text { so I want to buy it. } \\
\text { 33. I attach importance to natural and fresh food. } \\
\text { 34. I usually go to a convenience store or supermarket where I can buy food through } \\
\text { a fast shopping channel. }\end{array}$ \\
\hline
\end{tabular}

Table 3. Evaluation Items of Happiness Visual Design Elements for Organic Food Packaging.

\begin{tabular}{|c|c|}
\hline Dimension & Question \\
\hline \multirow{6}{*}{$\begin{array}{l}\text { Meaning and } \\
\text { Design Image }\end{array}$} & 1. Happiness organic food packaging needs to give people positive energy. \\
\hline & 2. Happiness organic food packaging needs to be carefully perceived and read. \\
\hline & 3. Happiness organic food packaging needs to resonate with my memory. \\
\hline & 4. Happiness organic food packaging needs the effect of calming the nerves. \\
\hline & $\begin{array}{l}\text { 5. Happiness organic food packaging needs a design image or element that requires } \\
\text { blessing (e.g., apple with the same sound for being safe and harmonious in Chinese) }\end{array}$ \\
\hline & $\begin{array}{l}\text { 6. Happiness organic food packaging needs to join the cultural elements of faith } \\
\text { (such as auspicious clouds and other happy totems.) }\end{array}$ \\
\hline \multirow{3}{*}{$\begin{array}{l}\text { Creation of Visual } \\
\quad \text { Situation }\end{array}$} & 7. Happiness organic food packaging needs a natural feeling. \\
\hline & 8. Happiness organic food packaging needs a happy image of reunion. \\
\hline & 9. Happiness organic food packaging needs to create a pleasant visual situation. \\
\hline \multirow{5}{*}{$\begin{array}{l}\text { Design Image and } \\
\text { Skills }\end{array}$} & 10. Happiness organic food packaging needs to be transparent to let me see the product. \\
\hline & $\begin{array}{l}\text { 11. Happiness organic food packaging needs to have the words "organic", etc., } \\
\text { in English and Chinese. }\end{array}$ \\
\hline & 12. Happiness organic food packaging needs to have a clean and simple design. \\
\hline & 13. Happiness organic food packaging needs bright colors to show freshness. \\
\hline & $\begin{array}{l}\text { 14. Happiness organic food packaging needs a small, intimate design that is easy to use } \\
\text { (e.g., easy-to-tear gap design, an illustration of the method of eating the food). }\end{array}$ \\
\hline \multirow{5}{*}{$\begin{array}{l}\text { Corporate Culture } \\
\text { and Brand } \\
\text { Certification }\end{array}$} & 15. Happiness organic food packaging needs a good corporate image. \\
\hline & 16. Happiness organic food packaging needs to have a production and sales resume \\
\hline & 17. Happiness organic food packaging needs to be in line with fair trade rules. \\
\hline & $\begin{array}{l}\text { 18. Happiness organic food packaging needs to be developed based } \\
\text { on environmental premises. }\end{array}$ \\
\hline & 19. Happiness organic food packaging needs to be recyclable or reusable. \\
\hline
\end{tabular}

\subsection{Experimental Samples}

The study was conducted on the perspective of visualization using sample graphic cards in the experiment. A wide variety of organic food packaging samples were collected. In this stage, meaning before the interviews, books from 2012 to 2015 were collected, including Pentawards and Packaging Design JPDA Member's Work Today, selected samples of organic food packaging were chosen. After a subjective evaluation of images, fifty-three images with unique characteristics such as clear and discernible style, color and material were selected while images that were analogous to others or unidentifiable were eliminated. Moreover, $\mathrm{KJ}$ method was used by four business design experts to remove samples with higher similarities. Finally, 30 organic food packaging images were chosen as representative samples for interview graphic cards. The representative samples were then printed out as $20 \times 20(\mathrm{~cm})$ color pictures for later data analysis samples. The evaluation of organic 
food packaging images was compared and analyzed using the KJ method [26]. Through four business design experts, packaging cases were classified into ten categories, that is, a white background portrays young style, bright color illustration style, simple and warm style, fresh bionic style, portrait situation style, interesting interaction style, elegant culture style, transparent fresh style, no color imitation and epoch science, and technology style as organic food packaging images (Table 4).

Table 4. Representative Samples of Organic Food Packaging.

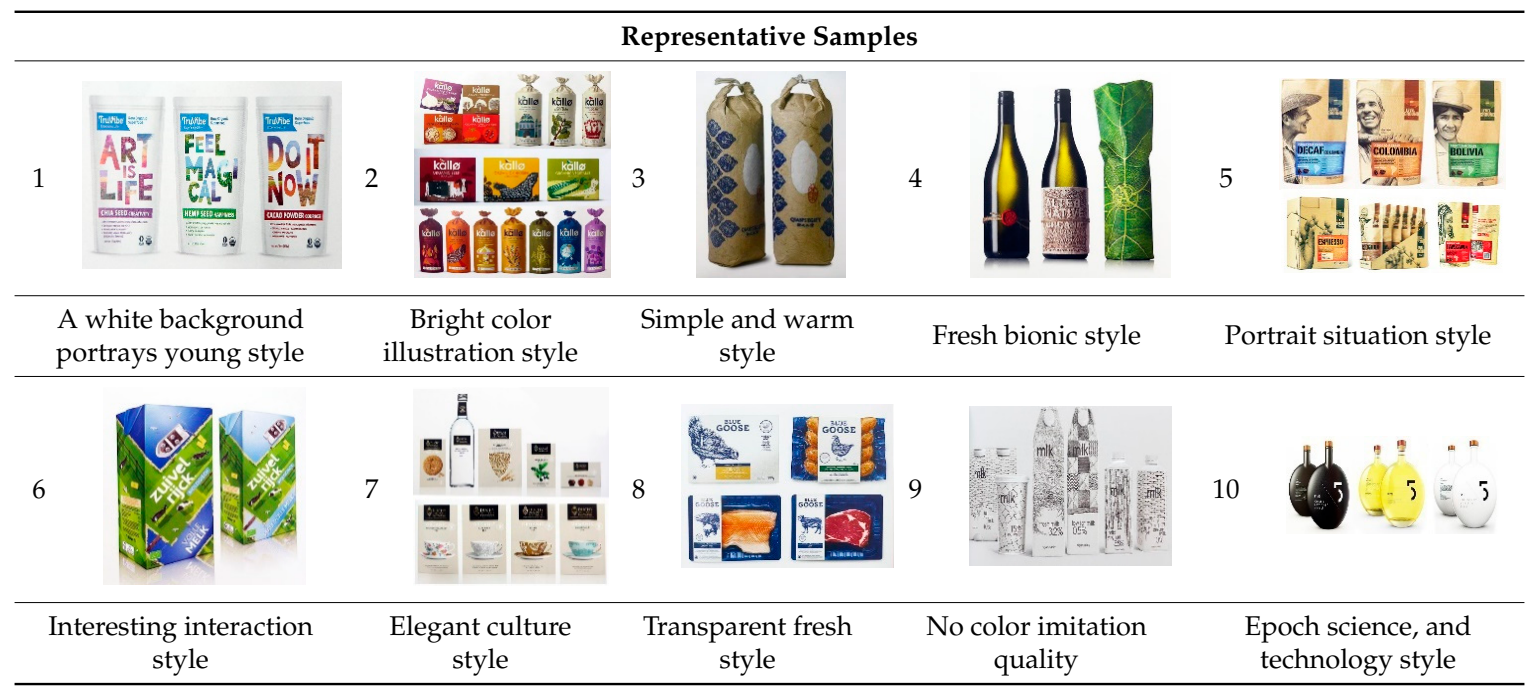

Regarding the visual image vocabulary of happiness packaging, before the expert interviews, 40 pairs of words related to happiness and visual design were collected through literature review, given to the above-mentioned four experts for reference, and the experts were requested to provide, select, or delete the descriptive vocabulary that best accorded the happiness of organic food packaging. After experts' opinions were collected, 9 pairs of the most representative descriptive words were extracted for questionnaire compilation (Table 5). This part used the representative adjective vocabulary, as selected by expert interviews, the extreme adjective scale of comparative meaning was placed at both ends, and the Semantic Differential method (SD method) $[27,28]$, used in conjunction with the organic food packaging samples, enabled the subjects to answer based on their subjective preferences.

Table 5. Descriptive Words for Organic Food Packaging.

\begin{tabular}{ccccccc}
\hline \multicolumn{7}{c}{ Adjective Pairs } \\
\hline 1. & Healing-Melancholy & 2. & Healthy-Harmful & 3. & Comfortable-Nervous \\
\hline 4. & Professional-Amateur & 5. & Unadorned-Pretentious & 6. & Non-toxic-Toxic \\
\hline 7. & Ease of mind-Uneasy & 8. & Environmentally friendly-Polluting & 9. & Novel-Traditional \\
\hline
\end{tabular}

\subsection{Experimental Procedures and Data Processing}

The experimental process includes a front-end questionnaire design and the determination of experimental samples. The processing of questionnaire data is based on data analysis, and subsequent inference, to show the distribution of 230 subjects' options for related questions. The questionnaire survey in this study is divided into four parts. The first part is the basic data of the subjects. The second part is matched with an AIO (Activity, Interest, Opinion) scale, and a Likert five-point scale is used as an evaluation method to obtain the lifestyle types of middle-aged and elderly people aged 40 to 65 years old. In the third part of the questionnaire, the semantic difference method (SD method) is used to provide adjectives with opposite meanings in the variables for the subjects to indicate their subjective feelings, where the purpose is to determine the happiness factors of middle-aged and elderly consumers 
for organic food packaging. The fourth part uses a Likert five-point scale as the evaluation method to explore the happiness of the visual design elements of middle-aged and elderly people for organic food packaging.

\subsubsection{Types and Characteristics of Lifestyle Groups of Middle-aged and Senior Citizens}

In this study, the AIO scale was used to analyze the sample structure and understand the basic appearance of the subjects, and then, factor analysis was used to cluster the items with high correlation into factors, in order to understand the characteristics of various lifestyles. Finally, cluster analysis was used to determine the grouping number and group characteristics of the middle-aged and elderly.

\subsubsection{Visual Image Assessment of Happiness Organic Food Packaging}

At this stage, the Semantic Differential method (SD method) was used in combination with organic food packaging samples to enable the subjects to answer according to their subjective preferences. In this research, there were 10 packaging samples in total, and the subjects provided subjective answers according to 9 groups of semantically opposite adjective words, in order to learn the subjects' preference for each sample.

\subsubsection{Evaluation of Visual Design Elements for Happiness Organic Food Packaging}

Based on expert interviews and the literature review, this study integrated the visual design elements of happiness in organic food packaging [29,30], drew up 19 questions for analysis, and used a Likert five-point scale for testing, where the purpose was to learn about the importance subjects attached to the design elements of happiness in organic food packaging. The scale consists of a set of statements, each of which has five answers, namely, "Strongly agree", "Agree", "Neutral", "Disagree", and "Strongly disagree", with the scores of 5, 4, 3, 2, and 1, respectively.

\subsubsection{Subjects}

In this study, people aged between 40 and 65 years old were selected as the sample, and a convenience sampling survey was conducted by questionnaire; where 232 questionnaires were distributed, and 230 valid questionnaires were obtained after excluding invalid questionnaires.

\section{Analysis of Results}

\subsection{Types and Characteristics of the Lifestyles of the Groups of Middle-aged and Elderly}

\subsubsection{Cluster Analysis of Lifestyles}

In order to analyze the lifestyle categories and differences of the subjects, this study first used factor analysis to simplify 34 questions regarding their lifestyles, in order to extract the main factors of the categories, and then, to understand the lifestyle characteristics of middle-aged and elderly people. In the analysis process, Principal Component Analysis (PCA) and the maximum variance method (Varimax) in factor analysis were used to extract the main factors [29]. The KMO value of this research scale is 0.792, and Bartlett's verification significance is 0.000 ; therefore, the data presented are suitable for factor analysis. After verification, the common factors were extracted through the PCA of factor analysis. The sum of the squares of the rotating shafts and the total load were selected, and an eigenvalue greater than one was taken as the screening criterion. The total explanatory variance is $60.761 \%$, and the lowest eigenvalue is 1.310 , thus, the screening criterion of the eigenvalue exceeding one is met. A total of 10 component factors were extracted, and then, according to the criterion of factor load selection, the items with a load of 0.4 were assigned to the factors. Therefore, seven factors were extracted and respectively explained as $12.527 \%, 8.041 \%, 8.618 \%, 7.870 \%, 7.041 \%, 7.231 \%$, and $5.580 \%$ of the variance, $56.908 \%$ of cumulative variance explained. 
Cluster analysis was carried out on the basis of the analysis of the seven lifestyle factors, as obtained from the above-mentioned factor analysis (Table 6). The cluster analysis method of k-means clustering was used to distinguish four types of lifestyle clusters. Table 7 shows the cluster scores of the seven lifestyle factors for the four types of groups. One Way ANOVA was used to explore whether there are differences between each group and their lifestyle factors, and according to the analysis results, significance can be seen $(P<0.05$ means significant) [31].

Table 6. Summary of Factor Analysis of Consumer.

\begin{tabular}{|c|c|c|c|c|}
\hline Factor Name & Question Items & $\begin{array}{l}\text { Explained } \\
\text { Variance\% }\end{array}$ & $\begin{array}{l}\text { Cumulative } \\
\text { Explained } \\
\text { Variance\% }\end{array}$ & $\begin{array}{c}\text { Factor } \\
\text { Loading }\end{array}$ \\
\hline \multirow{6}{*}{ Advocacy of food } & 31. I think the government should be committed to food safety checks. & 12.257 & 12.257 & 0.728 \\
\hline & $\begin{array}{l}\text { 20. If products are accompanied by production and marketing } \\
\text { certification, it can make the company aware of its responsibilities. }\end{array}$ & & & 0.704 \\
\hline & 28. I think people should continue to make progress and study. & & & 0.658 \\
\hline & 19. I pay attention to the diet health of my family members and myself. & & & 0.520 \\
\hline & $\begin{array}{l}\text { 24. I will try my best to do everything best, whether I am } \\
\text { good at it or not. }\end{array}$ & & & 0.492 \\
\hline & 18. I doubt the authenticity of the advertisement for a new product. & & & 0.409 \\
\hline $\begin{array}{l}\text { Safety independence and } \\
\text { self-confidence }\end{array}$ & 27. I will not hesitate in doing things, but will be more decisive. & 8.041 & 20.568 & 0.743 \\
\hline \multirow[t]{5}{*}{ Caring for Health } & 21. I have regular health checks. & 8.618 & 29.186 & 0.694 \\
\hline & $\begin{array}{l}\text { 16. I often provide the latest health information and trends to friends } \\
\text { and relatives. }\end{array}$ & & & 0.677 \\
\hline & 1. I often go shopping in organic or raw food stores. & & & 0.485 \\
\hline & $\begin{array}{l}\text { 15. It is very important for me to absorb the latest } \\
\text { health-related information. }\end{array}$ & & & 0.484 \\
\hline & 30. When buying food, I will read the ingredients of the food carefully. & & & 0.409 \\
\hline \multirow[t]{2}{*}{ Lohas and intellectual } & 17. I will buy products recommended by nutrition experts or scholars. & 7.870 & 37.056 & 0.768 \\
\hline & $\begin{array}{l}\text { 9. In order to balance the intake of nutrients, I will eat } \\
\text { healthcare food regularly. }\end{array}$ & & & 0.657 \\
\hline \multirow{2}{*}{ Hedonism } & $\begin{array}{l}\text { 7. In order to improve the enjoyment of life, it is worth } \\
\text { spending more money. }\end{array}$ & & & 0.625 \\
\hline & 6. When I see something I like; I will not hesitate to buy it. & & & 0.461 \\
\hline \multirow[t]{4}{*}{ Loyalty to the brand } & $\begin{array}{l}\text { 4. Before shopping, I will make a list of foods to be } \\
\text { purchased in advance. }\end{array}$ & 7.231 & 51.328 & 0.705 \\
\hline & 5. We should shop around to avoid losses in shopping. & & & 0.692 \\
\hline & 25. I am a cautious person and I have to plan everything. & & & 0.557 \\
\hline & $\begin{array}{l}\text { 3. I will particularly prefer to buy food or merchandise } \\
\text { of the same brand. }\end{array}$ & & & 0.476 \\
\hline \multirow[t]{3}{*}{ Willingness to share } & 13. I like to prepare meals with family and friends at home or outside. & 5.580 & 56.908 & 0.631 \\
\hline & 12. Although I have eaten dinner, I still want to have snacks. & & & 0.585 \\
\hline & $\begin{array}{l}\text { 26. It is easy for me to have a pleasant chat with people } \\
\text { I meet for the first time. }\end{array}$ & & & 0.536 \\
\hline
\end{tabular}


Table 7. Cluster Factor Dimensions of Consumer Lifestyle Values.

\begin{tabular}{ccccccc}
\hline Factor Dimension & Cluster 1 & Cluster 2 & Cluster 3 & Cluster 4 & F value & $\boldsymbol{P}$ value \\
\hline Advocacy of food Safety & 0.43214 & -5.57825 & 0.96627 & 0.59369 & 41.771 & 0.000 \\
\hline Independence and self-confidence & 2.18873 & 0.29824 & -2.70277 & -1.97807 & 4.025 & 0.008 \\
\hline Caring for health & -3.25763 & 1.58035 & -0.14538 & -0.38747 & 22.216 & 0.000 \\
\hline Lohas and intellectual & -1.27756 & 0.11547 & 0.60362 & -2.92475 & 40.526 & 0.000 \\
\hline Hedonism & 2.96468 & -0.90702 & -0.72083 & -1.61009 & 29.633 & 0.000 \\
\hline Loyalty to the brand & 1.12061 & -0.50796 & -2.18423 & 3.29353 & 15.672 & 0.000 \\
\hline Willingness to share & -1.33518 & -2.14488 & 1.32178 & 2.46788 & 3.675 & 0.013 \\
\hline
\end{tabular}

The significance of each factor is 0.000 , and the $P$ value must be less than 0.05 to reach the significant level of discrimination ability, and all factors meet the significant level. The higher the positive coefficient, the more importance is attached to this factor. The higher the negative coefficient, the less importance is attached to this factor. The following shows the significant characteristics of each group (Table 8):

1. Self-actualization Group

The "independence and self-confidence", "hedonism", and "loyalty to the brand" factors of Cluster 1 are positive, and at the center of the cluster, while the "Caring for Health" factor, the "Lohas and intellectual" factor, and the "willingness to share" factor are negative, and at the center of the cluster. Therefore, this group is named the "self-actualization group", with a total sample of 41 people, accounting for $17.8 \%$.

2. Caring For Health Group

As shown in Table 7, the "independence and self-confidence" factor, the "Caring for Health" factor, and "Lohas and intellectual" factor of Cluster 2 are positive, and at the center of the cluster, while the "advocacy of food safety" factor, the "hedonism" factor, the "loyalty to the brand" factor, and the "willingness to share" factor are negative, and at the center of the cluster. Therefore, this group is named the "Caring for Health group", with a total sample of 14 people, accounting for $6.1 \%$.

3. Lohas Food Safety Group

The "advocacy of food safety" factor, the "lohas and intellectual" factor, and "willingness to share" factor of Cluster 3 are positive, and at the center of the cluster, while the "independence and self-confidence" factor, the "Caring for Health" factor, and the "loyalty to the brand" factor are negative, and at the center of the cluster. Therefore, this group is named the "Lohas Food Safety group", with a total sample of 124 people, accounting for $53.9 \%$.

4. Extroverted Loyalty Group

The "advocacy for food safety" factor, the "loyalty to the brand" factor, and "willingness to share" factor of Cluster 3 are positive, and at the center of the cluster, while the "independence and confidence" factor, the "Caring for Health" factor, the "Lohas and intellectual" factor, and the "hedonism" factor are negative, and at the center of the cluster. Therefore, this group is named the "extroverted loyalty group", with a total sample of 51 people, accounting for $22.2 \%$. 
Table 8. Distribution of Cluster.

\begin{tabular}{ccc}
\hline Cluster & Sample & Percentage \\
\hline Cluster 1-Self-actualization Group & 41 & 17.8 \\
\hline Cluster 2-Caring For Health Group & 14 & 6.1 \\
\hline Cluster 3-Lohas Food Safety Group & 124 & 53.9 \\
\hline Cluster 4-Extroverted Loyalty Group & 51 & 22.2 \\
\hline Total & 230 & 100 \\
\hline
\end{tabular}

\subsubsection{Analysis of the Relationship between Demographic Variables and Lifestyle Groups}

The demographic variables of this study include 10 items: gender, age, marital status, occupation, education, monthly income, place of living, smoking, weekly exercise, and weekly eating out (Tables 9-11). The correlations between the lifestyle cluster and demographic variables described, as follows:

1. Cluster 1: Self-actualization Group

The middle-aged and elderly members of the self- actualization group have an independent character in handling affairs, do not mind the idea of a third party, are sincere in personality, do not defend themselves, and are confident and satisfied with themselves. In terms of shopping, they will not hesitate to buy things they like, as they believe that it is worthwhile to spend money to improve their enjoyment of life and quality of life, and they are willing to spend a higher amount of money on nutritious, natural, and safe foods to protect their health. They are willing and able to improve their living environment, and are very satisfied with their current life.

Among them, most are married middle-aged people aged 40 to 49 , with university education, and most have a monthly income of over NT $\$ 60,000$. The service industry is the largest occupation, and most of them have never smoked. They have an exercise frequency of less than two days per week and the eating-out habit of more than five days per week.

2. Cluster 2: Caring for Health Group

The middle-aged and elderly people of the Caring for Health group have the habit of regular health examinations, often pay attention to health-related trends and information, and will share obtained information with their relatives and friends. In addition, they often go to organic or raw food stores to shop. As they are used to reading information or data first, and use such information to determine the value of health, they must carefully read the information, as well as the contents and ingredients related to products, when purchasing food.

Among them, most are generally married middle-aged people aged 40 to 44 , with senior high school education. Most of them have a monthly income of NT\$40,000 to NT\$ 50,000. The manufacturing and service industry account for the largest occupations, and most of them have never smoked. They have the exercise frequency of less than two days per week and the eating-out habit of more than five days per week.

3. Cluster 3: Lohas Food Safety Group

The middle-aged and elderly people of the Lohas Food Safety group are very concerned about the government's handling of food safety issues, and pay attention to the relevant certificates, such as the checks and certifications of the quality control responsibility of enterprises for their products. As they are skeptical and afraid of unfamiliar product advertisements, the enterprise and brand image of food companies are the important basis for them to include when judging whether or not to purchase products. Therefore, although they will eat health food regularly to achieve balanced nutrition, when products are recommended or endorsed by nutrition experts or scholars, they will have more confidence in these products. Fresh and natural food is very important; in addition to improving the health of themselves and their families, they believe that eating organic food is to treat earth well and have the concept of environmental protection. 
They care about the health of themselves and their families, thus, the middle-aged and elderly members of this group will actively learn to make progress both inside and outside themselves, and will always try their best at everything, whether they are good at it or not. This group accounts for $54 \%$ of the total sample, are generally women, and the age range is 45 to 54 years old. Most people of this cluster are married, have an education level of mostly university, and most have monthly income above NT\$60,000. Most of the occupations in this group are in the service industry, and most never smoked. Most of them have the weekly exercise frequency of less than 2 days, and an eating-out habit of three to five days per week.

4. Cluster 4: Extroverted Loyalty Group

The middle-aged and elderly members of the extroverted loyalty group are accustomed to planning their work and have the same attitude towards shopping, meaning they are good at making purchase lists in advance before shopping. Therefore, in addition to preferring to buy products of the same brand, they also shop around to ensure that they do not spend a higher price than before to buy their usual products. This group is outgoing and not shy with strangers, and can easily chat with new people. Although they eat dinner, they still want to eat snacks, and are happy to meet friends for tea. They like to prepare meals at home, or go out for dinner and enjoy the pleasure of meeting people.

There are the same number of men and women in this group, they are generally between 40 and 54 years old, and their education is university. The average monthly income is below NT\$30,000 to NT $\$ 50,000$, and NT\$20,000, the most common occupation is service industry, and most have never smoked. Most of them have the weekly exercise frequency of less than two days, and an eating-out habit of more than five days a week. 
Table 9. The Characteristics of Lifestyle Clusters (\%).

\begin{tabular}{|c|c|c|c|c|c|c|c|c|c|c|c|c|c|c|c|}
\hline \multirow{2}{*}{ Cluster } & \multicolumn{2}{|c|}{ Gender } & \multicolumn{6}{|c|}{ Age } & \multicolumn{5}{|c|}{ Education } & \multicolumn{2}{|c|}{ Marital Status } \\
\hline & Male & Female & $40-44$ & $45-49$ & $50-54$ & $55-59$ & 60-64 & $65+$ & Junior High School & Senior High School & University & Master & Doctor & Single & Married \\
\hline Cluster 1-Self-actualization Group & 7.8 & 10 & 6.5 & 6.1 & 3.5 & 0.9 & 0.9 & 0 & 1.3 & 4.8 & 9.1 & 2.6 & 0 & 3 & 14.8 \\
\hline Cluster 2-Caring For Health Group & 3.9 & 2.2 & 3.9 & 0.9 & 0.9 & 0.4 & 0 & 0 & 0.4 & 3 & 1.7 & 0.4 & 0.4 & 1.3 & 4.8 \\
\hline Cluster 3-Lohas Food Safety Group & 22.6 & 31.3 & 12.6 & 18.3 & 16.1 & 5.2 & 1.7 & 0 & 2.2 & 11.3 & 30.4 & 9.6 & 0.4 & 8.7 & 45.2 \\
\hline Cluster 4-Extroverted Loyalty Group & 10.9 & 11.3 & 6.5 & 6.5 & 5.2 & 2.2 & 1.3 & 0.4 & 1.7 & 7 & 10.9 & 1.7 & 0.9 & 3 & 5.7 \\
\hline
\end{tabular}

Table 10. The Characteristics of Lifestyle Clusters (\%).

\begin{tabular}{|c|c|c|c|c|c|c|c|c|c|c|c|c|c|}
\hline \multirow[b]{2}{*}{ Cluster } & \multicolumn{4}{|c|}{ Occupation } & \multicolumn{6}{|c|}{ Monthly Income } & \multicolumn{3}{|c|}{ Place of Living } \\
\hline & Manufacturing & $\begin{array}{c}\text { Service } \\
\text { Industry }\end{array}$ & $\begin{array}{l}\text { Public Servant } \\
\text { Industry }\end{array}$ & $\begin{array}{c}\text { Between } \\
\text { Jobs/Retire }\end{array}$ & $\begin{array}{l}<\mathrm{NT} \\
20000\end{array}$ & $\begin{array}{l}\text { NT20000- } \\
\text { NT30000 }\end{array}$ & $\begin{array}{l}\text { NT30000- } \\
\text { NT40000 }\end{array}$ & $\begin{array}{l}\text { NT40000- } \\
\text { NT50000 }\end{array}$ & $\begin{array}{l}\text { NT50000- } \\
\text { NT60000 }\end{array}$ & NT60000+ & North & Middle & South \\
\hline $\begin{array}{c}\text { Cluster } \\
\text { 1-Self-actualization Group }\end{array}$ & 4.4 & 8.3 & 2.6 & 2.6 & 0.4 & 2.1 & 3.5 & 3 & 3 & 5.7 & 5.7 & 2.6 & 9.6 \\
\hline $\begin{array}{c}\text { Cluster 2-Caring For } \\
\text { Health Group }\end{array}$ & 2.2 & 2.2 & 1.7 & 0 & 1.3 & 0.4 & 0.9 & 1.7 & 0.4 & 1.3 & 1.3 & 2.2 & 2.6 \\
\hline $\begin{array}{l}\text { Cluster 3-Lohas Food } \\
\text { Safety Group }\end{array}$ & 12.6 & 25.2 & 9.6 & 6.5 & 6.5 & 6.1 & 8.7 & 7 & 9.1 & 16.5 & 20.4 & 9.6 & 23.9 \\
\hline $\begin{array}{l}\text { Cluster 4-Extroverted } \\
\text { Loyalty Group }\end{array}$ & 5.7 & 7.8 & 5.7 & 3.0 & 4.6 & 3.5 & 4.3 & 4.3 & 2.1 & 3.5 & 8.7 & 4.8 & 8.7 \\
\hline
\end{tabular}

Table 11. The Characteristics of Lifestyle Clusters (\%).

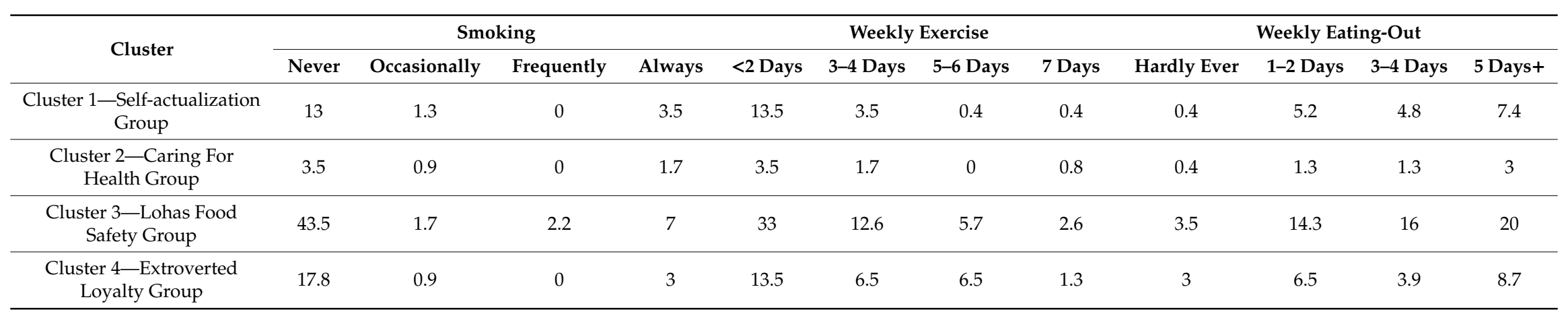




\subsection{Analysis of Happiness Visual Design Elements of Organic Food Packaging for the Middle-aged} and Elderly Population

\subsubsection{Assessment of Happiness of Lifestyle Groups for Sample Visual Images}

According to the average data of the visual imagery vocabulary, all groups have positive feelings towards the happiness of the samples. The higher the average, the higher the overall ranking of the packaging samples, which means that the happiness factor in a single cluster is more inclined to the right of the positive descriptive vocabulary. The higher the ranking and overlap of the samples, the more positive happiness the organic food packaging samples are believed to have among all lifestyles. Secondly, the comparative average analysis method was used to sum up the differences in the adjective vocabulary of happiness for the 10 representative samples of different lifestyles, and a Line Chart was used to observe the happiness evaluation of each cluster for the visual images of the samples, as shown in Table 12.

Table 12. Differences in Happiness Visual Images between Lifestyles.

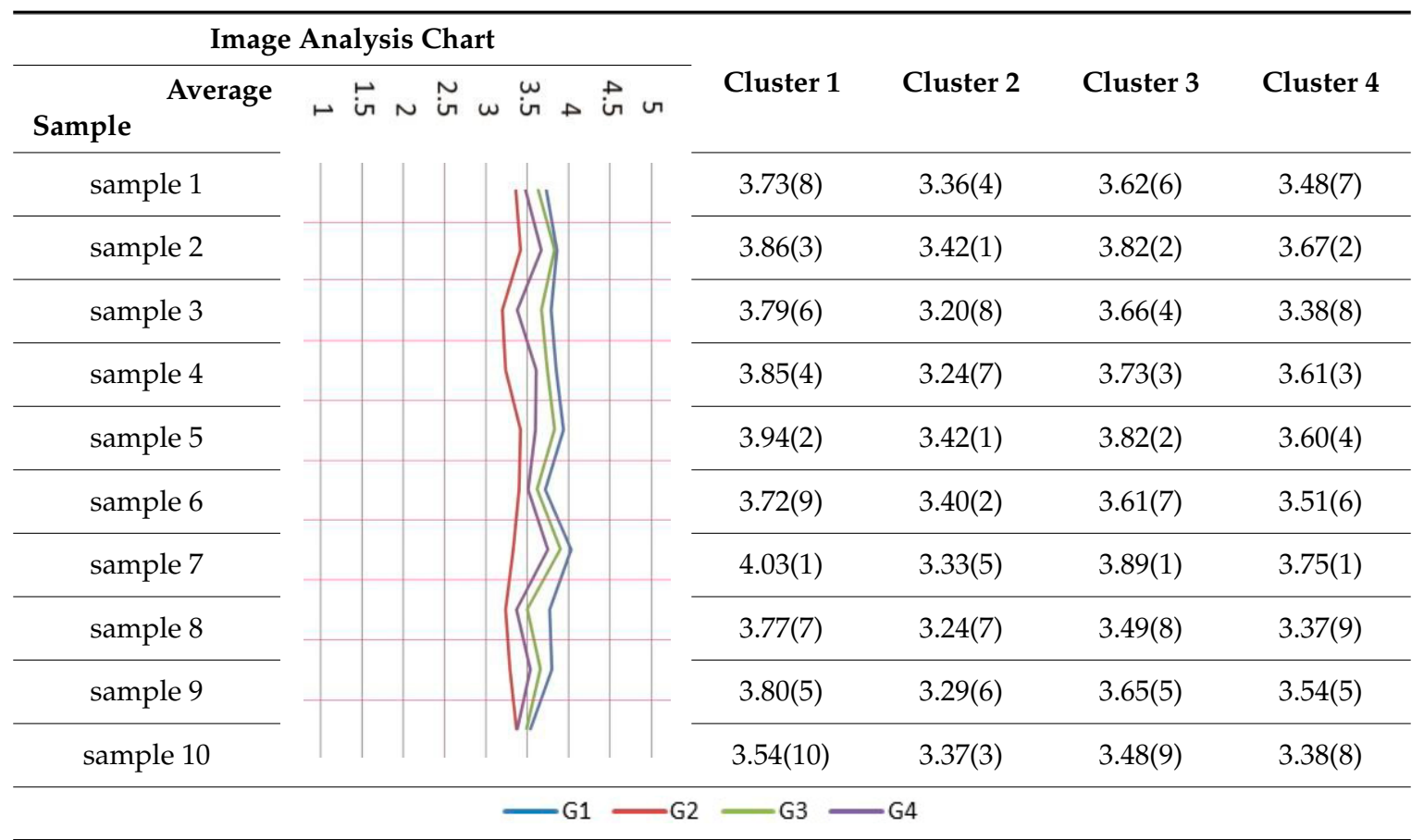

* The closer the average value to a positive value of five, the more positive the adjective; the closer the average value to a positive value of 1 , the more negative the adjective. * The ranking of happiness feelings is shown in brackets, with (1) as the highest level; in the order of (2), ... and (10) is the lowest. * Cluster 1 is the Self-actualization Group, Cluster 2 is the Caring for Health Group, Cluster 3 is the Lohas Food Safety Group, and Cluster 4 is the Extroverted Loyalty Group.

The "Self-actualization Group", "Lohas Food Safety Group", and "Extroverted Loyalty Group" think that organic food packaging with the greatest happiness is Sample 7; while the "Caring for Health group" thinks that Sample 2 and Sample 5 are the organic food packages with most happiness among the 10 samples (Table 13). The samples that each group believes are most suitable for happiness are summarized and described, as follows:

1. Influential Factors of Happiness in Organic Food Packaging of "Self-actualization Group", "Lohas Food Safety Group", and "Extroverted Loyalty Group"

The "Self-actualization group", "Lohas Food Safety group", and "Extroverted Loyalty Group" think that organic food packaging with the greatest happiness is Sample 7 (Table 13). Sample 7 has a more healing and comfortable design, and its overall packaging base takes yellow and gray as the overall tone, thus, the golden brand name is pressed on the black color block to emphasize 
the brand, and the pictures of food materials and edible utensils are used as the main vision, which are mainly presented in monochromatic, brilliant, and low color saturations, thus, enabling people to intuitively judge the characteristics of the products. Different cups and saucers are used as a way to identify tastes, which aim at establishing a novel brand image. Based on the above, the sense of happiness that Sample 7 gives the subjects includes being healthy, reassuring, environmentally friendly, healing, comfortable, and novel. As the "Self-actualization Group" is willing to spend money to improve its enjoyment and quality of life, and has the will and ability to improve its living environment, it has a high acceptance for fashionable food packaging. Sample 7's happiness of health, peace of mind, and environmental protection is in line with the health, food safety, and environmental protection issues, as emphasized by the "Lohas Food Safety Group". Sample 7 focuses on the main vision of the product's contents, as supported by the obvious brand name. This typesetting design mode is a theme story with images on the top and bottom, which enables the "Extroverted Loyalty Group" to more intuitively identify conventional brands, products, items, or tastes according to the overall vision, and they prefer to buy goods of the same brand. In order to ensure that their usual goods will not be bought at a higher price, the group will compare the goods with similar goods. This group can easily have a pleasant chat with new people, is happy to meet friends for tea, likes to prepare meals at home or dine out, and enjoys the pleasure of contact with people. Although this group has eaten its main meal, it still wants to eat snacks and is happy to relax while eating.

2. Influential Factors of Happiness in Organic Food Packaging of "Caring for Health Group" The "Caring for Health Group" thinks that Sample 2 and Sample 5 are the happiest (Table 13); this group pays attention to physical health, absorbs and shares health-related information from time to time, and likes to go to organic or raw food stores for shopping. When purchasing food, this group carefully reads the information, contents, and ingredients related to the product, in order to understand the health knowledge for good health care. Thus, this group is different from the middle-aged or elderly of other lifestyles, as it takes special care of its own health and disease prevention.

Sample 2 has a colorful and bright overall color; the color of the outer package can be directly linked with the agricultural product contents. This brand series of products are in the same design form, accounting for 1:2 and 1:3 of the aspect ratio. Its materials are vertical paste bottom square box packaging and reusable waterproof paper bags. The main vision of Sample 5 uses farmers as the product spokesmen, indicating that the product has a quality assurance person, which makes this group feel safe and comfortable when eating. The packaging color and texture are made of moist and rough waterproof kraft paper, which creates an environment-friendly image of recycled paper. The overall packaging material structure is a single package of vertical soft packaging material with reusable sealing clips, which can reduce the waste of food materials, maintain the freshness of food, and show the food safety factors expected by this group. In addition, the concrete photos of Sample 5's farmer spokesmen also give the "Caring for Health Group" the happiness of health, peace of mind, and environmental protection.

Based on the above, both Sample 2 and Sample 5 use concrete and semi-concrete illustrations and photos as design elements in an attempt to create quality assurance at the source of production and marketing, as well as the naturalness of the place of production, in order that the people in the "Caring for Health Group" have the opportunity to judge the quality of products or choose trusted products themselves. 
Table 13. Representative Samples and Descriptions of Happiness of Each Group.

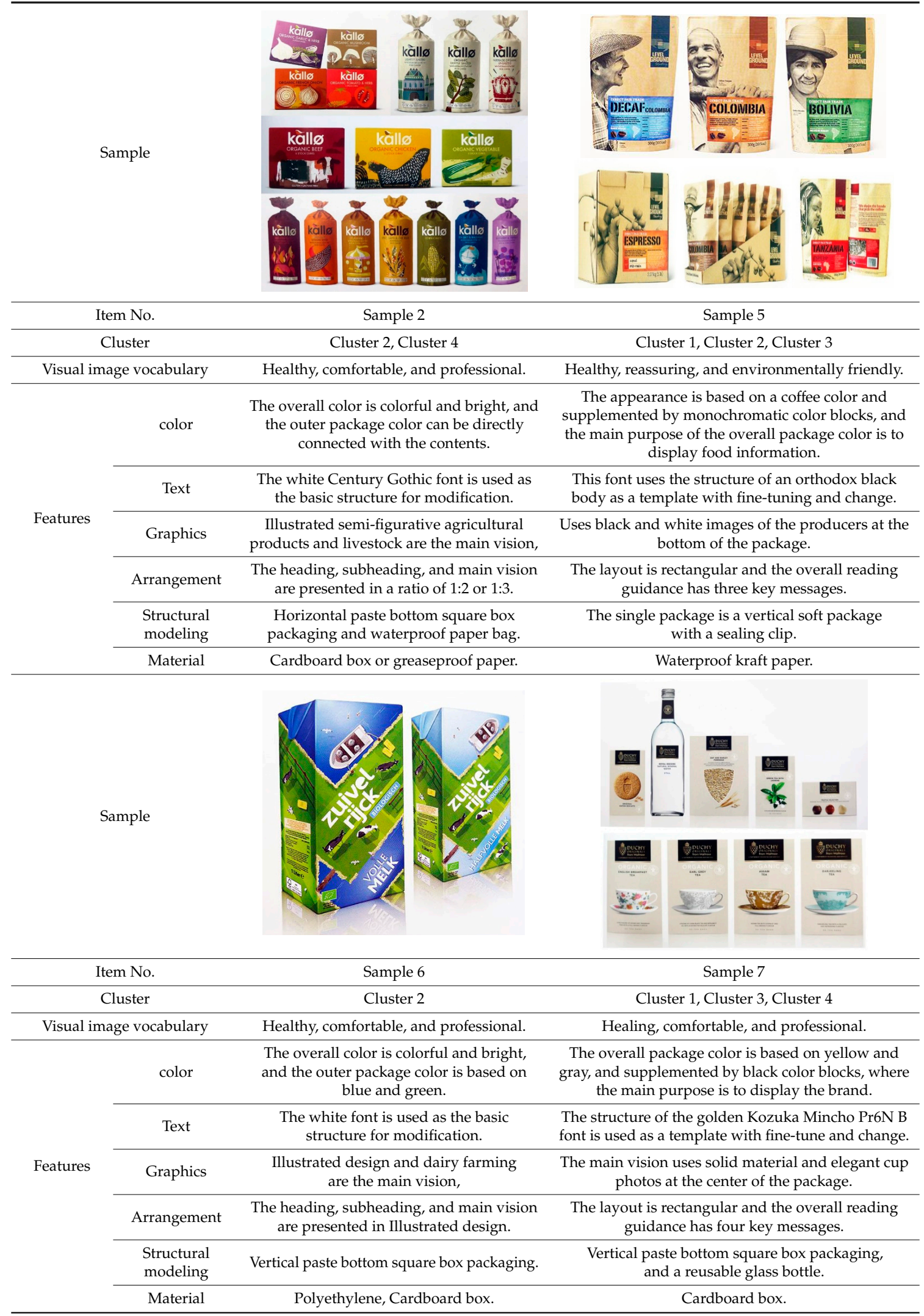

* Cluster 1 is the Self-actualization Group, Cluster 2 is the Caring for Health Group, Cluster 3 is the Lohas Food

Safety Group, and Cluster 4 is the Extroverted Loyalty Group. 


\subsubsection{Analysis of the Differences between Lifestyle Groups and Happiness Design Elements}

This study is basic research on the demand for happiness in organic food packaging, and includes packaging vision, packaging structure and materials, and the internal and external culture of the enterprise. Its main purpose is to understand the factors and elements of visual happiness, as required by middle-aged and elderly people of different lifestyles. Using organic and raw foods for dietary treatment not only improves the overall environment and quality of life, it also enables middle-aged and elderly people to protect their bodies and enrich their hearts, thus, enhancing the national humanistic spirit.

As industry experts believe that there is a problem with Taiwan's food safety, organic food manufacturers use packaging to mark that their product is different from other products. However, this packaging raises the cost of the product. In today's market, the design of packaging for organic food strives to present a feeling of being back to nature. As the products in this market are becoming more and more segmented, we also need to precisely target the needs of the consumer groups and product positioning. According to the expert interviews, when enterprises are able to understand the characteristics of consumers through their lifestyle, they can effectively communicate with consumers and increase product sales opportunities.

Based on the contents of the expert interviews and literature review, this study used a Likert five-point scale to conduct consumer questionnaires, and one-way ANOVA and the comparative average method were used to analyze the significant differences and factor needs among the clusters, and to rank the importance of their factors. According to analysis of the difference between the design elements of different lifestyle groups and happiness, as shown in Table 14, the significant design elements include 13 questions with question numbers $1,3,4,5,7,9,12,14,15,16,17,18$, and 19.

1. Attention of "Self-actualization Group" to Organic Food Packaging Happiness Visual Design Elements The "Self-actualization Group" expects happiness organic food packaging to give them positive energy, natural feeling, and considerate design, in order to render them more convenient to eat than other groups; for example, the design of easily torn gaps or the illustration of eating methods. In addition, presenting a good corporate image and doing a good job of fair trade with producers within the enterprise are also the design elements of happiness packaging that this group pays close attention to. Among them, the design elements of happiness organic food packaging that this group pays the most attention to are, from high to low, natural feeling and compliance with fair trade rules, structural packaging and icon design that contain positive energy allows people to conveniently eat, and a good corporate image.

2. Attention of "Caring for Health Group" to Organic Food Packaging Happiness Visual Design

Elements The "Caring for Health Group" expects happiness organic food packaging to have happiness design images or elements, and clean and simple design more than any other group. In addition, good corporate image, product production, and marketing history are also the elements of happiness packaging design that this group pays close attention to. Among them, the elements of happiness organic food packaging design that this group pays most attention to are, from high to low, hollowed-out design that allows people to see the contents of the product, clean and simple designs with attached production and marketing resume, convenient structural packaging and icon design, the word "Organic" displayed on the packaging in Chinese and English, as well as a good corporate image.

3. Attention of "Lohas Food Safety Group" to Organic Food Packaging Happiness Visual Design Elements The "Lohas Food Safety Group" expects happiness organic food packaging to comply with fair-trade laws, be developed based on the premise of environmental protection, and use recyclable or reusable packaging materials more than other groups. In addition, the hollowed-out packaging design, production, and marketing history that can prove product quality are the design elements of happiness packaging that this group pays attention to. Among them, the elements of the happiness organic food packaging design that this group pays most attention 
to are, from high to low, the hollowed-out design that allows people see the contents of the product, clean and simple design, attached production and marketing history certificate, the word "organic" is displayed in Chinese and English on the packaging, and uses recyclable or reusable packaging materials.

4. Attention of "Extroverted Loyalty Group" to Organic Food Packaging Happiness Visual Design Elements The "Extroverted Loyalty Group" expects happiness organic food packaging to have thoughtful design to allow people to eat it more conveniently than other groups; for example, the design of easily torn gaps or an illustration of the eating method. In addition, natural and friendly eating environment and environment-friendly packaging materials are also the design elements of happiness packaging that this group is concerned about. Among them, the design elements of happiness organic food packaging that this group is most concerned about are, in the order of requirements from high to low, smart and thoughtful design to allow people to eat conveniently, creation of overall natural feeling, conformity to good corporate image, and the use of recyclable or reusable packaging materials.

Table 14. Analysis of Differences between Different Lifestyle Groups and Happiness Design Elements.

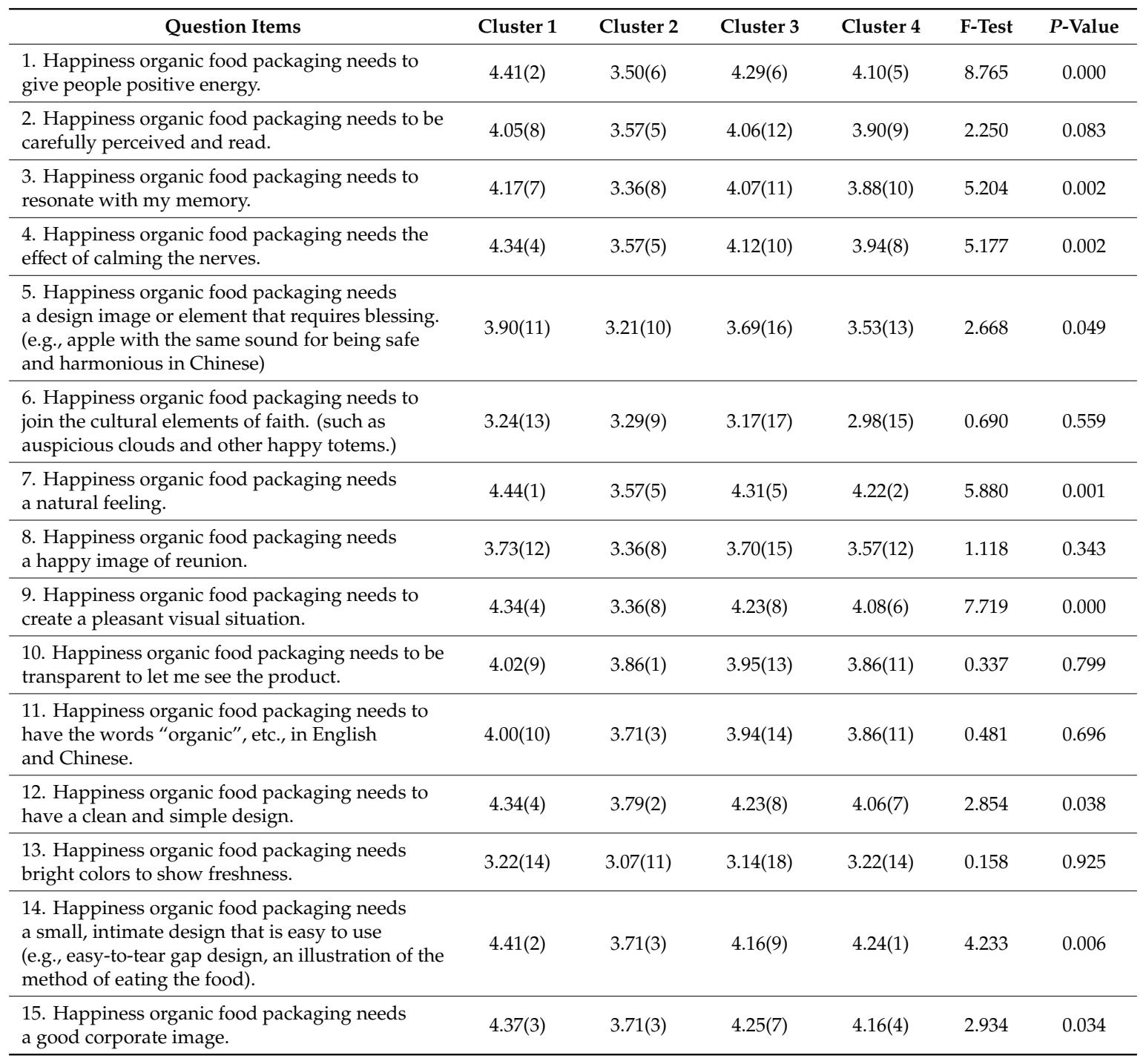


Table 14. Cont.

\begin{tabular}{|c|c|c|c|c|c|c|}
\hline Question Items & Cluster 1 & Cluster 2 & Cluster 3 & Cluster 4 & F-Test & $P$-Value \\
\hline $\begin{array}{l}\text { 16. Happiness organic food packaging needs to } \\
\text { have a production and sales resume. }\end{array}$ & $4.34(4)$ & $3.79(2)$ & $4.36(4)$ & $4.08(6)$ & 4.098 & 0.007 \\
\hline $\begin{array}{l}\text { 17. Happiness organic food packaging needs to be } \\
\text { in line with fair trade rules. }\end{array}$ & $4.44(1)$ & $3.64(4)$ & $4.41(1)$ & $4.20(3)$ & 6.303 & 0.000 \\
\hline $\begin{array}{l}\text { 18. Happiness organic food packaging needs to be } \\
\text { developed based on environmental premises. }\end{array}$ & $4.29(5)$ & $3.43(7)$ & $4.38(3)$ & $4.16(4)$ & 7.683 & 0.000 \\
\hline $\begin{array}{l}\text { 19. Happiness organic food packaging needs to be } \\
\text { recyclable or reusable. }\end{array}$ & $4.22(6)$ & $3.71(3)$ & $4.40(2)$ & $4.20(3)$ & 3.798 & 0.011 \\
\hline \multicolumn{7}{|c|}{$\begin{array}{l}\text { * The closer the average value is to a positive value of } 5 \text {, the higher the agreement. The closer the average value } \\
\text { is to a positive value of } 1 \text {, the higher the disagreement. * The ranking of happiness feelings is shown in brackets, } \\
\text { with (1) as the highest level; ranking from high to low in the order of rank (2), .., and (10). * Cluster1 is the } \\
\text { Self-actualization Group, Cluster } 2 \text { is the Caring for Health Group, Cluster3 is the Lohas Food Safety Group, and } \\
\text { Cluster4 is the Extroverted Loyalty Group. }\end{array}$} \\
\hline
\end{tabular}

\section{Conclusion and Recommendations}

\subsection{Conclusion}

According to expert interviews, while it can be seen that there is no specific style or standard for the packaging of organic food; designers generally like to use simple and elegant or clean and clear colors to present the simple and pure feeling of nature. Regarding the factors influencing the happiness of organic food packaging, experts believe that visual software at the spiritual level, such as brand image shaping and the appeal and atmosphere created by the vision, as well as those that can be carefully perceived and read, can give people positive energy and generate happiness. This happiness factor is consistent with literature. In addition, experts believe that happiness organic food packaging needs natural simplicity, as well as clean and simple design, to create a natural and fresh atmosphere for products. Moreover, the four experts with many years of practical experience believe that, in terms of packaging hardware structure and materials, simple and easy-to-read guiding diagrams are convenient for consumers to eat, and the hollowed-out design allows consumers to see the reassuring design of the product contents, as well as improving the use of packaging materials, in order to enhance food safety and create a friendly food environment that can render more in-depth happiness through design. In addition, regarding the development of organic food packaging, it is considered that the conscience and brand image of the enterprise are important, meaning it is necessary to attach importance to the development of products and product packaging materials, as based on the premise of environmental protection. Fair trade between enterprises and producers is especially important, as the production process of organic food is very difficult. If the production and marketing records are added to the packaging, it can give consumers peace of mind and trust, and provide a channel for communication between consumers and enterprises.

The "Caring for Health Group" believes that happiness organic food packaging is healthy, reassuring, and environmentally friendly. As this group pays special attention to health, it not only shares and absorbs relevant information on health, it also goes to organic or raw food stores to shop. When shopping, this group pays special attention to the information, content, and composition related to the product; therefore, concrete, semi-concrete photos, illustrations, and other design elements can facilitate their own judgment on the quality of the product, and whether or not to choose to trust the product.

The "Lohas Food Safety Group" believes that happiness organic food is packaged in a healthy, simple, and environment-friendly way. As this group pays attention to family members' health, and regularly eats healthy food to obtain balanced nutrition, it holds a skeptical and conservative attitude towards unfamiliar product advertisements, thus, the brand image of the enterprise is the main factor affecting the shopping habits of this group. Therefore, if there is a recommendation or endorsement of a product by nutrition experts or scholars, this group will have a sense of trust, and the "Lohas Food 
Safety Group" accounts for as much as $50 \%$ of the total sample. From this, it can be inferred that, there are three major issues that most middle-aged and elderly people attach importance to: health, food safety, and environmental protection. If they can perceive health, peace of mind, and environmental protection in organic food packaging, most middle-aged and elderly consumers will also feel happiness.

\subsection{Recommendations}

The following suggestions were proposed based on the research results for industries, package designers, and future studies. Firstly, as happiness covers a wide range of fields, the current definition of happiness is ambiguous, experts and scholars have different definitions, and the characteristics and factors of concern are also different. Although we can determine the commonness of human happiness through research, and conduct inductive analysis to understand it, the reality is that everyone's feelings are different. In order to improve the accuracy of research, it is suggested that future research focuses on the scope of the research, in order to minimize the differences as much as possible. Secondly, as the sampling of the packaging samples in this study were screened and summarized by senior design experts, the style was considered as a criterion for summary, and only the representative packaging of each style was taken in the screening, thus, the number of samples is small. It is suggested that a detailed study of differences can be made for a specific style or trait sample in the future, in order to obtain more subtle and accurate factors of happiness.

Author Contributions: J.C.T. provided good research advice and supervision; H.T.C. provided good research advice and revised the paper; S.B.C. collected and analyzed the data, and wrote the original paper; and all the authors read and approved the manuscript.

Acknowledgments: Thanks to the anonymous reviewers and all the editors in the process of manuscript revision.

Conflicts of Interest: The authors declare no conflict of interest.

\section{References}

1. Moody's Investors Service, Inc. Available online: https://www.moodysanalytics.com/ (accessed on 6 February 2014).

2. Chou, M.C.; Wang, W.Y. Differences between designers and consumers in comprehending communication designs for food packaging. J. Des. 2007, 12, 21-41.

3. Lin, S.Y.; Chen, S.F. The content analysis in packaging design and marketing strategy of the senior health foods. J. Healthy Life Success. Aging 2014, 6, 25-42.

4. Wang, P.N. Package Design; Chwa: New Taipei City, Taiwan, 2015.

5. Kenya, H. Design of KenyaHara; Seibundo Shinkosha: Tokyo, Japan, 2014.

6. Hung, Y.M.; Liu, P.C. A Study on Psychology Marker and Association of Application Icons. In Proceedings of the Orange Beneficence-International Design Conference of Smart Living for Elderly, Taiwan, Taipei, 24 November 2013.

7. Cheng, J.C. A Research on the Design of Eudaimonia Products; National Yunlin University of Science and Technology: Yunlin, Taiwan, 2015.

8. Desmet, P.M.A. Faces of product pleasure: 25 positive emotions in human-product interactions. J. Des. 2012, $6,1-29$.

9. DGBAS. Social Indicators 2012; Directorate General of Budget, Accounting and Statistics, Executive Yuan: Taiwan, Taipei, 2013.

10. Chan, S.H.; Tsai, W.C. Measuring Subjective Well-being; NPF Commentary: Taipei, Taiwan, 2012.

11. Pieter, M.A.D.; Anna, E.P. Positive design: An introduction to design for subjective well-being. Int. J. Des. 2003, 7, 5-19.

12. Wang, C.F.; Ouy, Y. The Study of gross national happiness. Sci. Technol. Policy Res. 2015, 509, 36-41.

13. Tang, H.C. Listen to Tang; Sungoodbook: New Taipei City, Taiwan, 2014.

14. Ching, J.I. The Influence of Interesting Snack Package Design on Consumers' Behavior; National Taiwan University of Arts: New Taipei City, Taiwan, 2010. 
15. Tsai, P.C. Evaluation of the Consumer Perception for the Package Design of the Organic Cosmetics; Ming Chuan University: Taipei, Taiwan, 2007.

16. Lin, P.C.; Chang, C.L. Theoretical foundation for pictogram communication systematization. J. Des. Sci. 2009, 12, 46-69.

17. Yen, J.; Lin, S.Y. A Study of the Variables of Packaging Design that Affect Brand Equity. J. Des. 2010, 15, 71-91.

18. Engel, J.F.; Blackwell, R.D.; Miniard, P.W. Consumer Behavior; Dryden Press: Chicago, IL, USA, 1993.

19. Arnold, K.; Bianchi, C. Relationship marketing, gender and culture: Implications for consumer behavior. Adv. Consum. Res. 2001, 28, 100-105.

20. Hsu, K.H.; Kung, F.H.; Chang, C.H.; Wang, Y.A. The effect of organic foods cognition and store image on purchase intention-From the points of consumers' view. J. Sport Health Leis. 2010, 17, 59-70.

21. Duffy, M.E. Determinants of health promoting lifestyles in older persons. J. Nurs. Scholarship. 1993, 25, 23-28. [CrossRef]

22. Citation, D.E. Subjective well-being. Psychol. Bull. 1984, 95, 542-575.

23. Bryła, P. Organic food consumption in Poland: Motives and barriers. Appetite 2016, 105, 737-746.

24. Lee, K.L.; Chen, J.H.; Yen, J. Construction of five senses design model—An example for foods package design. J. Sci. Technol. 2008, 17, 159-168.

25. Cresswell, J.W. Research Design: Qualitative, Quantitative, and Mixed Methods; SAGE Publications Ltd.: New York, NY, USA, 2002.

26. Kawakita, J. Kawakita Jiro Method; Chuokoron-shinsha: Tokyo, Japan, 1986.

27. Uwe, F. Qualitative Sozialforschung; Rowohlt-Taschenbuch-Verlag: Reinbek bei Hamburg, Germany, 2010.

28. Wu, M.L. SPSS and the Application and Analysis of Statistics; Book City: New Taipei City, Taiwan, 2013.

29. Lien, T.C.; Cheng, H.F. The Development of the well-being Scale for Elders in Taiwan. Guid. Q. 2015, 51, 29-37.

30. Huang, Y.T. The Effects of Product Knowledge, Channel Selection and Organic Certification on Consumer Value Perception and Purchase Intention-A Case of Organic Food in Taiwan; National Cheng Kung University: Tainan, Taiwan, 2013.

31. Hair, J.F.; Rolph, R.E.; Tatham, L.R.; Black, W.C. Multivariate Data Analysis; Prentice-Hall: Upper Saddle River, NJ, USA, 1998.

(C) 2019 by the authors. Licensee MDPI, Basel, Switzerland. This article is an open access article distributed under the terms and conditions of the Creative Commons Attribution (CC BY) license (http://creativecommons.org/licenses/by/4.0/). 